\title{
Maternal fish oil supplementation in lactation: effect on developmental outcome in breast-fed infants
}

\author{
Lotte LAURITZEN ${ }^{a *}$, Marianne H. JøRGENSEN ${ }^{b}$, Sjúrdur F. OLSEN ${ }^{c}$, \\ Ellen Marie STRAARUP ${ }^{d}$, Kim F. MICHAELSEN ${ }^{a}$ \\ ${ }^{a}$ Center for Advanced Food Studies, Department of Human Nutrition, The Royal Veterinary \\ and Agricultural University, Rolighedsvej 30, 1958 Frederiksberg C, Denmark \\ b Department of Pediatrics, Rigshospitalet, Blegdamsvej 3, 2100 Copenhagen, Denmark \\ c Maternal Nutrition Group, Danish Epidemiology Science Centre, Statens Serum Institut, Artillerivej 5, \\ 2300 Copenhagen, Denmark \\ d Center for Advanced Food Studies, Biochemistry and Nutrition Group, BioCentrum-DTU, \\ The Technical University of Denmark, Bygn. 224, 2800 Kgs. Lyngby, Denmark
}

(Received 19 October 2004; accepted 20 December 2004)

\begin{abstract}
Docosahexaenoic acid (DHA) accumulates in the brain during the 1st and 2nd years of life. The objective of this study was to see if an increased content of DHA in breast-milk via maternal fish oil (FO)-supplementation affects mental development in term infants. one hundred twenty-two Danish mothers with a habitual fish intake below the population median were randomized to $4.5 \mathrm{~g} \cdot \mathrm{d}^{-1}$ of FO or olive oil (OO) for the first four months of lactation. Fifty-three mothers with habitual fish intake in the highest quartile were included as reference group. The effect of the resulting increase in infant DHA-intake and RBC-DHA level was assessed on problem solving ability at nine months and language at one and two years of age. Infants in the three groups performed equally well on the problem test and no association was observed between problem solving and erythrocyte-DHA at four months. Passive vocabulary at one year was lower in the children of the FO- compared with the OOgroup $(P<0.05)$, but no differences were found at two years of age. Word comprehension at one year was inversely associated with erythrocyte-DHA at four months. The trial indicate a small effect of DHA levels in breast-milk on early language development of breast-fed infants.
\end{abstract}

docosahexaenoic acid / breast-milk / infant development / long-chain n-3 fatty acid / optimal dietary intake

Abbreviations: AA: arachidonic acid; CDI: communicative development inventory; DHA: docosahexaenoic acid; FO: fish oil; LCPUFA: long-chain polyunsaturated fatty acid; OO: olive oil; PUFA: polyunsaturated fatty acid; RBC: red blood cells.

\section{INTRODUCTION}

Early intake of $n-3$ polyunsaturated fatty acids (PUFA) may affect the mental devel- opment of infants [1]. The cellular membranes of the central nervous system contain uniquely high levels of long-chain polyunsaturated fatty acids (LCPUFA),

\footnotetext{
* Corresponding author: 11@kvl.dk
} 
especially docosahexaenoic acid (DHA, $22: 6 n-3)$. During the central nervous system growth spurt, rapid accretion of DHA takes place [2]. Formula-fed infants, who do not receive exogenously preformed DHA, have lower levels of DHA in their central nervous system membranes $[3,4]$. This difference in fatty acid composition may contribute to the observed difference in mental abilities between breast-fed and formulafed children. A meta-analysis has shown an approximate 3 IQ-point benefit of breastfeeding when compared to infant formulas [5]. Some randomized supplementation studies, comparing term infants fed formulas enriched with DHA or DHA and n-6 PUFA (arachidonic acid (AA) or gammalinoleic acid) or standard infant formulas, have shown beneficial effects on cognitive development [6-9], but other studies did not confirm this [10-14]. Furthermore, one study found a transient negative effect on linguistic development in infants supplemented with DHA $[11,14]$.

Human milk supplies breast-fed infants with LCPUFA. In supplementation studies formula-fed infants are usually provided with DHA in levels equivalent to that in typical breast-milk in Western societies. However, the DHA level of human milk varies by close to a factor of 50 [15]. This variation is primarily caused by differences in maternal fish intake. Fish oil (FO)-supplementation of lactating mothers effectively increases breast-milk DHA levels [16-19]. At present there is insufficient scientific evidence to determine whether the variation in DHA level in breast-milk has functional implications for the breast-fed infant. Small cross sectional studies have observed relationship between the DHA-content of human milk, or levels of DHA in infant or maternal plasma, and the sleep pattern, visual acuity, cognitive abilities, speech perception and language development of breast-fed infants [14, 15, 20-24]. Furthermore, studies supplementing lactating mothers with marine oils have shown that the DHA-intake of breast-fed infants may have beneficial effects on mental development [25-27]. The present maternal post-natal FO-supplementation trial was performed in Denmark where the population has a high intake of marine fatty acids compared to that in many other Western countries [35] and thus, higher levels of breast-milk DHA [1].

The cognitive abilities of infants have in many studies been assessed by global measures of infant development such as the Bayleys mental development index. However the effect of DHA may be more clearly elucidated by more specific test of cognitive development [28]. The Infant Planning Test is specifically designed to determine meansend problem solving at 8-11 months of age and has previously in a small randomized study been shown to reflect DHA+AA-supplementation $[8,9]$. Early language development has in a single combined randomized and cross-sectional study been reported to be associated with early DHA-intake [14]. The effect of DHA-intake was observed at 14 months of age using a parent-report instrument, the MacArthur Communicative Development Inventory (CDI) [14] but was not found at 39 months of age with developmentally appropriate tests of receptive and expressive language [11]. Until this effect on language development has been confirmed in other randomized studies this could be as chance finding.

The aim of the present indirect postnatal infant DHA-supplementation study was to examine whether FO-supplementation of lactating mothers could affect growth and development of their infants, primarily visual acuity. The study was designed as a double-blind intervention study randomizing mothers with a habitual fish intake below the population median to daily supplementation with FO or olive oil (OO) for four months, starting in the first week after delivery. A reference group of mothers with a habitual fish intake in the upper quartile of the population were also included. The effect on the fatty acid composition of breast-milk and infant erythrocytes (RBC) and visual acuity has been published [29], as have effects on later blood pressure and 
body composition [30, 31]. FO-supplementation increased the DHA content of breastmilk and infant erythrocytes (RBC), but this was not found to improve infant visual acuity [29]. Also no difference was found in blood pressure at 2.5 years of age [31], but the body mass index of the children at that age was significantly higher in the FOsupplemented group [30]. The aim of the present paper is to evaluate the effect of maternal FO-supplementation on infant development, problem solving at nine month and early language acquisition.

\section{MATERIALS AND METHODS}

\subsection{Participants, trial and supplements}

The study protocol was approved by the Scientific-Ethical Committees for Copenhagen and Frederiksberg (KF 01-300/98) and all participants gave written consent to participate after the study had been explained to them. The group size in this randomized trial was based on a power calculation for infant visual acuity, as explained in a previous paper [30]. Around $80 \%$ of the infants completed the mental follow-up measures reported in the present paper, resulting in a power to show a difference between the randomized groups of around 0.6 SD of functional outcome. The details of the study design and recruitment procedure, which have been reported elsewhere [29], are described briefly here.

During 1999, participants were selected from among pregnant women recruited for the Danish National Birth Cohort [32] based on their intake of n-3 LCPUFA. Women with a fish intake below the population median $\left(<0.4 \mathrm{~g} \mathrm{n}-3\right.$ LCPUFA $\left.\cdot \mathrm{d}^{-1}\right)$ were recruited along with pregnant women with a fish intake in the upper quartile of the population (>0.8 n-3 LCPUFA. $\mathrm{d}^{-1}$ (HFgroup)). In order to participate in the trial the women were required to have an uncomplicated pregnancy, a normal prepregnancy body mass index $\left(<30 \mathrm{~kg} \cdot \mathrm{m}^{-2}\right)$, no metabolic disorders, an intention to breastfeed for at least four months and to start on the supplement regimen within two weeks after delivery. Furthermore, the newborns had to be healthy, singleton, term infants with normal weight for gestation [33] and an Apgar score $>7$ five minutes after delivery. One hundred and twenty-two and 53 of the women with a low and high fish intake, respectively, fulfilled all these criteria.

After birth 62 and 60 mothers with a fish intake below the median were randomly assigned to supplementation with FO and OO, respectively. The supplementation was started $9 \pm 3$ days after delivery and continued throughout the first four months of the lactation period. The experimental group received $4.5 \mathrm{~g}$ of $\mathrm{FO}$ (containing $1.5 \mathrm{~g}$ of n-3 LCPUFA, 60\% DHA). The control group was given a similar amount of $\mathrm{OO}$. Microencapsulated FO and $\mathrm{OO}$ (from BASF Health and Nutrition A/S, Ballerup, Denmark) were supplied in müsli-bars (produced by Halo Foods Ltd., Tywyn Gwynedd, Wales, UK). As an alternative the women were also offered the supplements in homemade cookies or oil capsules (a gift from Lupe/ProNova Biocare, Lysaker, Norway). The women that completed the intervention period reported that they had taken on average $88 \pm 9 \%(n=99)$ of the supplements during the entire four-month supplementation period (or during the period of breastfeeding, if shorter than the intended four months). Investigators and families were blinded to the randomization during data collection and analysis.

One hundred mother-infant-pairs completed the intervention trial and 50 motherinfant pairs from the HF-group were followed during this four-month period. All drop-outs were due to choices made by the participants (as explained in [29]), none of the mothers were excluded for lack of compliance with supplements or the breast-feeding request. During this period 107 mothers complied with the criteria for exclusive breastfeeding. Infants not fully breast-fed were not excluded from the study, but we estimated 
Table I. Characteristics of infants of mothers with a high fish intake (HF) and mothers with a low fish intake, who were supplemented with olive oil (OO) or fish oil (FO) during the first four months of lactation. Data are given as mean \pm SD or percentage of the study population. No significant differences among the groups.

\begin{tabular}{|c|c|c|c|}
\hline & \multicolumn{2}{|c|}{ Randomized trial } & \multirow{2}{*}{$\begin{array}{c}\text { Reference } \\
\text { HF }\end{array}$} \\
\hline & $\mathrm{OO}$ & FO & \\
\hline No. at 9 months & 47 & 53 & 48 \\
\hline Sex (\% boys) & 51 & 64 & 52 \\
\hline Gestational age (weeks) & $40.2 \pm 1.3$ & $40.2 \pm 1.2$ & $40.2 \pm 1.2$ \\
\hline Birth weight (kg) & $3.58 \pm 0.43$ & $3.64 \pm 0.46$ & $3.62 \pm 0.44$ \\
\hline Age at problem solving (weeks) & $38.5 \pm 0.5$ & $38.6 \pm 0.6$ & $38.6 \pm 0.7$ \\
\hline Head circumference at 9 months $(\mathrm{cm})$ & $45.3 \pm 1.4$ & $45.8 \pm 1.5$ & $45.8 \pm 1.4$ \\
\hline Mean parental education (years) & $14.1 \pm 2.1$ & $14.1 \pm 2.0$ & $14.1 \pm 2.3$ \\
\hline Siblings (\% with siblings) & 55 & 40 & 56 \\
\hline DHA in breast-milk at 4 months ( $\%$ of fatty acids) & $0.4 \pm 0.2$ & $1.3 \pm 0.7$ & $0.7 \pm 0.3$ \\
\hline \multicolumn{4}{|l|}{ Estimated human milk intake during intervention } \\
\hline (\% of total intake) & $93 \pm 19$ & $86 \pm 28$ & $93 \pm 20$ \\
\hline
\end{tabular}

(as previously described in [29]) to which extent breast-milk covered their needs (Tab. I). The efficiency of the maternal supplementation with respect to changes in infant n-3 LCPUFA intake was assessed by determination of the fatty acid composition in breast-milk and infant RBC as previously described [29].

\subsection{Outcome measures}

The effects of the intervention on the mental development of the infants was assessed on motor function from birth to nine months of age, ability for means-end problem solving at nine months of age and language at one and two years. Mothers and infants visited the Research Department of Human Nutrition at two, four and nine months after delivery. Developmental milestones in motor function were assessed by interviews at each of the visits, using questions like "Has your baby learned to sit since the last visit?" and "How many months was she/he, when she/he sat for the first time?" All infants from the randomized trial participated at the nine month follow-up visit along with 48 of the infants from the HFgroup. The characteristics of these infants are shown in Table I.

\subsubsection{Means-end problem solving}

The problem solving ability of the infants were tested at nine months of age (36.6-40.6 weeks) by The Infant Planning Test by Dr P. Willatts (Dept. of Psychology, University of Dundee, UK) [8, 9]. The infant sat on the parent's lap and was presented with a two-step problem, independently (pretests) and combined as described by Dr Willatts et al. [9]. The tests were performed by one trained tester $(72.5 \%)$ or in her absence by one of two trained tester stand-ins (17.2 and $10.3 \%)$. We aimed at three trials for each pretest (final $2.7 \pm 0.7$ ) followed by five test trials on the combined problem (final $3.7 \pm 1.8$, equal in the three groups). All trials were recorded on videotape and behavior was scored for evidence of intention (\% intentional and scores from 0-6 in each step) as described [9]. Intentional solutions are defined as problems solved with a score of at least one in all 
steps. All videotapes were scored independently by two trained observers. The initial inter-observer correlation for intention score was $r=0.94$ and the proportion of agreements in the assessment of intentional solutions was $68 \%$. Infant performance was reanalyzed by both observers independently if the two observers disagreed on number of intentional problem solutions or with more than three points in intention score. The final inter-observer correlation for intention score was $r=0.96$ and the proportion of agreements on the identification of intentional solutions was $81 \%$. Results are based on the average of the final scores of both observers. Successful results on the problem-solving test was obtained for 122 children ( $89 \%$ of those tested). For most of the infants without successful completion, the infants were upset or unwilling to engage in the test $(n=14)$ and for two infants the tape recordings were lost. Based on the size of the present study and published variation in means-end problem solving at 9 months [9] the study had power to show a difference of 2 in intention score.

\subsubsection{Language assessment}

Infant linguistic development was assessed at one and two years of age by MacArthur Communicative Development Inventory (CDI) forms for infant (8-16 month old children) and toddler (16-30 month), respectively. The CDI-forms were translated into Danish in collaboration with Dr D. Bleses from the Odense Language Acquisition Project (Inst. of Language and Communication, University of Southern Denmark) with permission from Dr L. Fenson (Developmental Psychology Lab., San Diego State University, CA, USA). The CDI is a parentreport instrument. The infant form evaluates language comprehension, early word production, and gestural communication. Language comprehension is assessed by whether the infant responds to "name", "no" or "there is mother" and from the number of phrases (of 26) and words (of 409) that the parent thinks the infant understands. The assessment of word production is based on whether the infant does lingual imitation and labeling and from the number of words spoken (of the 409). Gestural communication was assessed by the use of gestures typical of early and later communicative development in infancy (of 18 and 45, respectively). The toddler form is designed to assess vocabulary (of 725 words) and grammatical skills and also includes a section on syntax and morphology. Grammatical skills are determined from the use of past, future, abstract, plural, possessive and past tense and the number of irregular and overregularized words (of 29 and 62, respectively). Syntax and morphology is assessed from whether the child combines words and from sentence length and complexity (selected number of complex members in 33 paired examples). The parents were asked to fill out the CDI forms when the child was 12 and 24 months old, respectively. The infant and toddler CDI-form were returned from 140 and 122 of the children, respectively. Forms, from which the age of the child at completion could not be determined due to missing dates or which were filled out when the infant was more than $10 \%$ older than intended ( $>13.2$ and $>26.4$ months, respectively) were excluded. Complete language data at one and two years of age was obtained from 131 and 111 children, respectively, hereof 89 and 71 in the randomized groups. No power calculation was possible for the MacArthur CDI, as Danish normal values has not been made and the previously reported association between infant DHA-intake and CDI is based on normalized data [14].

In a small validation study, eleven pairs of Danish parents with 11-15 month-old children were asked both to fill out the infant CDI form totally independently of each other. These 11 children had an average vocabulary production and comprehension of 10 and 65 words, respectively. There was an overall significant association between the language scores assessed by the mothers and fathers $(P$-values for six out of 
ten sections in the questionnaire were $<0.05$ and the remaining $<0.16, \mathrm{r}$ for noncategorical variables $0.33-0.62$ ) and no bias (all ten $P$-values $>0.10$ ). Scores for language comprehension, word production and gestural communication were significantly correlated with one another in both the validation group $(P<0.05$ for eight out of ten correlations between the non-categorical variables $r=0.52-0.89$ ) and the study group (all 10 correlations $P<0.001$, $r=0.25-0.52)$.

\subsection{Statistical analysis}

All participants were included in comparisons of included and non-included children, girls and boys, first children and children with siblings, group characteristics and developmental milestones. These analysis were performed as those of the two randomized groups or if more that three groups by Kruskal-Wallis and ANOVA for Gaussdistributed and non-Gauss-distributed variables, respectively. The main focus of the analysis in this report was to compare the two randomized groups. The problem solving ability and language scores of the infants in the two randomized groups were compared using $\chi^{2}$-test for nominal data, Mann-Whitney U-tests for ordinal data or non-Gauss-distributed data (intentional solutions, word production and early gestures at one year and number of irregular and overregularized words and sentence complexity at two years of age) or Student $t$-test for all other variables (intention score, vocabulary and phrase understanding and number of late gestures at one year and vocabulary and sentence length at two years of age). Univariate association between the developmental outcome measures and mean parental education, age at testing and duration of breast-feeding in the entire group of children was investigated by correlation analysis (Pearson for intention score and Kendall's for all other variables). The same tests were used to look for associations between development scores and the DHA content of infant $\mathrm{RBC}$ at the end of the intervention in the randomized groups. Furthermore, the possible difference in intention score between the randomized groups was compared by ANOVA controlling for factors with known influence on mental development: sex, mean parental education, no of siblings, duration of breast-feeding, age at testing, and a sexgroup-interaction term. Similar multiple regression analysis for the association between outcome and RBC-DHA also included the estimated human milk intake.

All statistical analysis was performed by SPSS (version 11.0, SPSS Inc., Chicago, USA). Quantitative results from separate groups are generally summarized as a mean \pm standard deviation (SD) or median (25th75th percentile) for non-Gauss-distributed variables.

\section{RESULTS}

The DHA-intake of the infants in the FOsupplemented group was increased 2.5 fold (Tab. I) and the DHA level in infant RBC at four months was increased by $40 \%$ [29].

All subjects that completed the intervention period participated in the nine month follow-up examination except one. The children with data on cognitive and linguistic development did not differ significantly from those who did not complete these tests with respect to gestational age, birth weight, sex, compliance or estimated human milk intake during the intervention period, parental education or number of siblings (data not shown).

No significant differences were observed among the three groups with respect to overall motor function (data not shown). The infants in the high fish intake, OO- and FO-supplemented groups were sitting without support at $6.5 \pm 0.8,6.4 \pm 1.0$ and $6.5 \pm$ 1.0 months of age respectively. At the ninemonth visit approximately $50 \%$ of the infants were crawling and $45 \%$ were standing with support.

The result of the Infant Planning Test is given in Table II. More than $60 \%$ of the 
Table II. Problem solving at nine months of age in the supplemented groups (fish oil group (FO) and olive oil group $(\mathrm{OO})$ ) and the reference group $(\mathrm{HF})$. Data are given as mean $\pm \mathrm{SD}$ or median (25th75 th percentile).

\begin{tabular}{lccc}
\hline & \multicolumn{2}{c}{ Randomized trial } & \multirow{2}{*}{ Reference } \\
\cline { 2 - 3 } & OO & FO & HF \\
\hline Exact age (weeks) & $38.5 \pm 0.5$ & $38.6 \pm 0.6$ & $38.6 \pm 0.7$ \\
No. on Infant Planning Test (boys:girls) & $38(20: 18)$ & $48(31: 17)$ & $42(23: 19)$ \\
\% with no intentional solutions & 63 & 65 & 62 \\
Median intentional solutions of entire problem & $0(0-20)$ & $0(0-39)$ & $0(0-20)$ \\
(\% of tests) & & & \\
Intention score entire problem & $4.3 \pm 3.6$ & $4.5 \pm 3.1$ & $4.5 \pm 3.3$ \\
Intention score boys & $4.9 \pm 3.6$ & $3.9 \pm 3.1$ & $5.0 \pm 3.6$ \\
Intention score girls & $3.7 \pm 2.5$ & $5.7 \pm 2.7 *$ & $3.9 \pm 2.8$ \\
\hline
\end{tabular}

* Significantly different from that in the OO-group $(P=0.024)$. Statistical comparisons were done only between the two randomized groups. The HF-group is shown as a reference group of mother with naturally high fish intake.

infants (equally distributed between the groups) were unable to solve the problem they were given with intention. No differences were observed between the intention scores of the two randomized groups (with all infants included or without those, who were estimated to be breast-fed $<50 \%$ during the intervention period).

No significant univariate association was found between intention score and the level of DHA in infant RBC at the end of the intervention (data not shown). A significant positive effect of parental education was observed on the intention score in the entire group of infants ( $r=0.175, P=0.049, n=$ 128). No significant difference between boys and girls was observed in the intention scores $(P=0.846, n=128)$ or percent intentional solutions $(P=0.265)$. However, in the randomized groups there was a significant interaction between sex and supplement in an ANOVA-analysis of intention score $(P=0.026$, including supplementgroup, sex, mean parental education, number of siblings and age at test; data not shown). When the group-comparisons were performed separately in each sex, then a significant positive effect of FO-supplementation was evident in the girls $(t$-test $P=0.024, n=35)$.
The univariate association between RBCDHA and intention score in the girls was $r=0.288(P=0.123, n=30)$.

More than $97 \%$ of the children responded to their name and "no" and $90 \%$ responded to "there is mother" and the distributions were similar in the groups (data not shown). Around $15 \%$ of the infants did lingual imitation and object labeling (Tab. III), which corresponds well with the number of words produced (typically $0-3$ in infants, who did not imitate and label, and 8-13 words in those, who did). A significant difference between the two randomized groups was observed in passive vocabulary at one year of age (Tab. III). In the randomized part of the study active vocabulary at one year of age was found to be significantly negatively associated with the DHA-level of infant $\mathrm{RBC}$ at the end of the intervention $(r=-0.204$, $P=0.016, n=69$ ).

At two years of age $>85 \%$ of the children had begun to combine words (equal in groups, data not shown) and to develop grammatical skills (marginally less in the FO-supplemented group $(P<0.10)$, Tab. III). There were no significant differences in vocabulary production or other language scores between the randomized groups at 
Table III. Linguistic development in the infants at one and two years of age. Linguistic development was assessed by the MacArthur Communicative Development Inventory (Danish). Data given as unadjusted mean scores \pm SD or median (25th-75th percentile).

\begin{tabular}{|c|c|c|c|}
\hline & \multicolumn{2}{|c|}{ Randomized trial } & \multirow{2}{*}{$\begin{array}{c}\text { Reference } \\
\text { HF }\end{array}$} \\
\hline & $\mathrm{OO}$ & FO & \\
\hline No. at 1 year of age (boys:girls) & $37(19: 18)$ & $52(33: 19)$ & $42(22: 20)$ \\
\hline Exact age (months) & $12.5 \pm 1.0$ & $12.3 \pm 0.2$ & $12.3 \pm 0.5$ \\
\hline Starting to talk $(\%)$ & 16 & 12 & 17 \\
\hline Early gestures (No.) & $11(9-12)$ & $11(8-12)$ & $12(10-13)$ \\
\hline Late gestures (No.) & $15 \pm 7$ & $14 \pm 6$ & $16 \pm 7$ \\
\hline Phrases understood (No.) & $11 \pm 6$ & $11 \pm 5$ & $11 \pm 5$ \\
\hline Vocabulary comprehension (No. of words) & $71 \pm 45$ & $54 \pm 37^{*}$ & $65 \pm 40$ \\
\hline Boys - Comprehension & $77 \pm 47$ & $44 \pm 34^{*}$ & $58 \pm 47$ \\
\hline Girls - Comprehension & $64 \pm 42$ & $68 \pm 37$ & $72 \pm 30$ \\
\hline Vocabulary production (No. of words) & $5(2-11)$ & $3(1-9)$ & $5(1-11)$ \\
\hline No. at 2 years of age (boys:girls) & $31(16: 15)$ & $40(26: 14)$ & $40(19: 21)$ \\
\hline Exact age (months) & $24.8 \pm 0.9$ & $24.7 \pm 1.1$ & $24.5 \pm 0.9$ \\
\hline Vocabulary production (No. of words) & $297 \pm 147$ & $242 \pm 170$ & $312 \pm 146$ \\
\hline Talk about "abstract” (\%) & 94 & 75 & 95 \\
\hline Use grammar (\%) & 32 & 25 & 40 \\
\hline Irregular words (No.) & $3(1-7)$ & $3(0-6)$ & $4(2-5)$ \\
\hline Overregularized words (No.) & $1(0-3)$ & $1(0-2)$ & $1(0-3)$ \\
\hline Length of longest sentences (No. of words) & $3.8 \pm 2.3$ & $3.3 \pm 1.9$ & $4.1 \pm 2.1$ \\
\hline Sentence complexity (No. of complex of a pair) & $3(0-10)$ & $1(0-7)$ & $5(1-8)$ \\
\hline Boys - Sentence complexity & $4.5(0-10)$ & $0.5(0-3)^{*}$ & $1.0(0-5)$ \\
\hline Girls - Sentence complexity & $3.0(0-10)$ & $4.0(1-13)$ & $7.0(3-11)$ \\
\hline
\end{tabular}

* Statistically significantly different from OO-group: $P=0.045, P=0.005, P=0.043$, respectively.

two years of age (Tab. III). Also no associations were observed between RBC DHAlevels and language at two years of age (data not shown).

Mean parental education was found to have a negative influence on word comprehension and possibly also on word production at one year of age $(r=-0.228, P=$ $0.009, n=131$ and $r=-0.115, P=0.075$, respectively). Girls had significantly higher vocabulary than boys at one as well as two years of age $(P=0.020$ and $P=0.011$, respectively). In the randomized groups a significant interaction between sex and sup- plement-group was observed in an ANOVAanalysis of vocabulary comprehension at one year of age $(P=0.034$, including supplement-group, sex, mean parental education, number of siblings and age; data not shown). When the randomized groups were compared in the two sex-subgroups, maternal FO-supplementation was found to have a significant negative effect on linguistic abilities in boys only (Tab. III). Boys in the FO-supplemented group also tended to have less word production of at one year of age, but this did not reach the level of significance $(P=0.065)$. No association was observed between word production at one 
year of age or sentence complexity at two years and DHA in RBC at the end of the intervention in the randomized boy sub-groups, but there was a trend towards a negative association to word comprehension at one year of age $(r=-0.309, P=0.059, n=38)$.

All language parameters at one and two years of age correlated significantly with one another in the randomized part of the study as well as in the entire study population (e.g., vocabulary comprehension at one year vs. production at two years of age $r=$ $0.206, P=0.003, n=99$, other correlations not shown). No association was observed between scores in the Infant Planning Test and language at one and two years of age (data not shown).

\section{DISCUSSION}

FO-supplementation of the lactating mothers in this trial resulted in a 2.5 -fold increase in the DHA-levels of the breastmilk [29]. This had no apparent effect on the problem solving ability of the infants at nine month of age, although it seemed to have a positive effect in girls. A previous maternal-supplementation trial found that a similar increase in breast-milk DHA was associated with a positive effect on the Bayley mental development index score at one year of age, which was no longer evident at two years [25]. A recent Norwegian study has shown that supplementation with cod liver oil during pregnancy and lactation resulted in an increased mental processing score at four years of age [26]. However, in another study, which supplied lactating American mothers with much lower doses of DHA than the other trials, no effects could be found on mental development during the first 2.5 years of life [27]. The results of DHA-supplementation trials with term formula-fed infants are conflicting with respect to the impact on mental development. One of the suggested causes of the conflict has been the specificity of the cognitive test [28]. The test we use in the present study assesses a specific cognitive type of behavior and is in this respect sim- ilar to the one used in the Norwegian study, whereas the other two trials have used global tests of infant development. Willatts et al. showed a beneficial effect of DHA and AA on means-end problem solving at nine and ten months of age in a small trial with formula-fed infants [8,9]. In that study the intention score at nine months of age was around seven with $36 \%$ intentional solutions. The intentions scores of the infants in the present study were for some reason lower. Willatts et al. found an effect of DHA + AA at nine months of age only in those infants who at three months had demonstrated poorer attention control [9]. Our results indicate an effect only in girls. We did not find that girls had higher intention scores than boys, but it is the general view that they with respect to most skills mature faster than boys. The test has to be in accordance with the maturational stage of the children and may better detect differences between infants at a specific stage of development. The apparent sex difference may be a coincidence not reflecting a difference in problem solving, but rather small sample size or other sex differences, e.g. in accordance with the test.

In a combined randomized and observational trial intake of DHA was shown to be associated with slower language acquisition in randomized formula-fed infants as well as in breast-fed infants [14]. To our knowledge, none of the previous maternal FO-supplementation trial has investigated the effect on language development in breast-fed infants. We found significantly lower verbal comprehension at 12 months in FO-supplemented group and an inverse dose response relationship between vocabulary at one year and the DHA levels in $\mathrm{RBC}$ after the intervention, both most pronounced in boys. No sex difference was reported in the previous study, but it fits the assumption that mental advantageous effects may be more pronounced in boys, who in general mature more slowly. From the previous report the effect of DHA on language development appears to be transient as no difference was found beyond the second 
year of life [11], which is in agreement with the results of our over-all group comparisons. However, we did find a significant correlation between language scores at one and two years of age, as also shown in previous data [34]. Also, although the difference was no longer significant, the children in the FO-group were the ones with the smallest vocabulary at two years of age and there was a significant difference in the boy-subgroup. Since fewer of the children were tested at two years of age the apparent lack of effect at two years could be explained by a type II error. In a second trial, in which the infant formulas were supplemented with slightly lower levels of DHA, Auestad et al. did not reproduce the negative effect on language development at 14 months of age [10]. Furthermore, a previous maternal DHA-supplementation trial did not observe any effect of a low-dose DHA-supplement during lactation (breast-milk DHA levels $0.2-0.4 \%$ of fatty acids) on linguistic and auditory milestones of the infants at 12 and 30 months of age [27]. The explanation for these inconsistencies could be a simple dose-response relationship, but more studies are needed to exclude that the negative association between DHA-intake and early language development is a chance finding.

The DHA concentration in breast-milk of the high fish intake group was in between that in the FO- and OO-supplemented groups. The language scores of the high fish group also tend to be intermediary to that in the two randomized groups, whereas no such pattern is apparent in the problem solving scores. A habitual high maternal fish intake would also affect the DHA supply during fetal development. Several studies have shown that DHA status during pregnancy or at delivery can affect infant cognitive development [20, 21]. The results of the Norwegian maternal FO-supplementation trial in which cod liver oil was provided from the 18th week of gestation indicate that the intrauterine DHA exposure is more important for mental development than that in post-natal life [26].
Not all infants in the present trial were exclusively breast-fed for the entire intervention period, which limits the impact of the maternal supplement on infant development. Unfortunately the estimated human milk intake was not equally distributed in the randomized groups, but was more prevalent in the FO-group and thus would tend to blur potential differences. Our trial was limited also by a relatively low success rate in the outcome measures (79-95\%), which has reduced the power of the study, especially when it comes to detecting differences that may be specific to one of the genders. With around 40 children in each of the groups for both outcomes this study had power to show a difference between groups of 0.6 SD. We observe a somewhat smaller significant group-difference in one of 12 numerical variables along with some differences in gender subgroups. These differences could be random positive findings, but show effects that are in agreement with previously published results. Much of the variation is caused by uncertainties in the test. None of the outcome tests that we used are standardized, validated test instruments and both are beset with a high degree of uncertainty. The Infant Planning Test depends on infant engagement and temperament and on a subjective assessment of infant performance. However, the inter-observer correlation for the intention score was high. Specific tests of complex cognitive behavior like the Infant Planning Test are critically dependent on the developmental stage of the children. We only used the test at one specific age and cannot judge if the match is optimal for detecting differences within the normal range for their age. We have not been able to perform a long-term follow-up on more validated childhood IQ tests.

The CDI forms have been translated into Danish only recently and have not yet been described with respect to normal values in the population. Furthermore, the CDI is a parent report instrument. Our data indicate that it provides a reasonably consistent picture of vocabulary. We found that the CDI-score at one year of age appears to be independent 
of the parent who filled out the questionnaire and that there was a significant correlation between the CDI-scores at one and two years of age. The Danish population has a high intake of n-3 LCPUFA compared to that in many other Western countries [35], which is reflected in relatively high levels of DHA and lower levels of n-6 PUFA in breast-milk and $\operatorname{RBC}[1,36]$. Despite this intervention trial has given evidence of effects on language development, body mass composition (30) and possible visual acuity [29] of an increase in maternal n-3 LCPUFA-intake, indicating that the n-3 PUFA needs of infants may be higher than assumed at the present.

It is hard to make any assumptions about the long-term effects of differences in cognitive and language development in the first year of life. The two-step problem-solving score at nine months has been shown to correlate positively with IQ and vocabulary scores later in childhood, although accounting for only a small proportion of the variance in later IQ [37, 38]. The predictive value of early language assessments with respect to later intellectual abilities is to our knowledge not known. Scott et al. interpreted the negative association between DHA intake of formula-fed infants and 14 month vocabulary as an adverse effect [14]. They could however not show any difference in linguistic skills or IQ at three years of age [11]. In the present study, vocabulary at one year of age was significantly associated with that at two years of age and the boys of the FO-supplemented mothers still had the poorest linguistic skills when they were two years old. Early language development was found to be negatively associated with mean parental education, in agreement with previous observations [39]. Empirically we would not expect low intellectual achievements later in life of children with highly educated parents. Thus, a negative effect of early DHA intake on language acquisition does not necessarily indicate an adverse effect. Cross-cultural comparisons of CDI-data indicate that Danish children have slow early language development compared to Swedish, Spanish and American children, but they appear to catch-up within the second year of life (D. Bleses, personal communication). This may be due to a high prevalence of day-care in Denmark or other cultural differences, but if early language development is influenced by DHA intake, then the relatively high Danish fish intake could contribute to this cultural difference.

\section{CONCLUSION}

Maternal FO-supplementation during the first four months of lactation was found not to have any beneficial effect on problem solving, although the data indicate that there may be an effect in girls. Maternal FOsupplementation was found to result in a reduction in vocabulary comprehension at one year of age, especially in boys. This effect may be transient since no or only limited differences were observed at two years of age. Word production at one year was associated with DHA levels in infant RBC at the end of the intervention. Thus, the results of this randomized trial indicate that the DHA-content of breast-milk may affect the mental development of breast-fed infants. Whether a slow early language acquisition represents an adverse effect is unknown.

\section{ACKNOWLEDGEMENTS}

We gratefully acknowledge Dietician, Majken Ege and Pediatric Nurses, Charlotte Mester and Heidi Eismark for collecting the data. Dr Peter Willatts (Dept. of Psychology, University of Dundee, UK) was involved in discussions on how to test mental outcome and taught us how to perform the problem solving test. Furthermore, Dr Dorthe Bleeses (Institute of language and Communication, University of Southern Denmark) is gratefully acknowledged for their translation and Danish adaptation of the MacArthur CDI, with kind permission from Dr Larry Fenson (Developmental Psychology Lab., San Diego State University, CA, USA). This 
study was financed by FØTEK - The Danish Research and Development Program for Food and Technology and BASF Aktiengesellschaft.

\section{REFERENCES}

[1] Lauritzen L, Hansen HS, Jørgensen MH, Michaelsen KF. The essentiality of long-chain n-3 fatty acids in relation to development and function of the brain and retina. Prog Lipid Res 2001, 40: 1-94.

[2] Martinez M, Mougan I. Fatty acid composition of human brain phospholipids during normal development. J Neurochem 1998, 71: 2528-2533.

[3] Byard RW, Makrides M, Need M, Neumann MA, Gibson RA. Sudden infant death syndrome: Effect of breast and formula feeding on frontal cortex and brainstem lipid composition. J Paediatr Child Health 1995, 31: 14-16.

[4] Farquharson J, Cockburn F, Patrick WA, Jamieson EC, Logan RW. Infant cerebral cortex phospholipid fatty-acid composition and diet. Lancet 1992, 340: 810-813.

[5] Anderson JW, Johnstone BM, Remley DT. Breast-feeding and cognitive development: a meta-analysis. Am J Clin Nutr 1999, 70: 525 535.

[6] Agostoni C, Trojan, Bellu R, Riva E, Giovannini M. Neurodevelopmental quotient of healthy term infants at 4 months and feeding practice: the role of long-chain polyunsaturated fatty acids. Pediatr Res 1995, 38: 262-266.

[7] Birch EE, Garfield S, Hoffman DR, Uauy R, Birch DG. A randomized controlled trial of early dietary supply of long- chain polyunsaturated fatty acids and mental development in term infants. Dev Med Child Neurol 2000, 42: 174-181.

[8] Willatts P, Forsyth JS, DiModugno MK, Varma S, Colvin M. Effect of long-chain polyunsaturated fatty acids in infant formula on problem solving at 10 months of age. Lancet 1998, 352: 688-691.

[9] Willatts P, Forsyth JS, DiModugno MK, Varma S, Colvin M. Influence of long-chain polyunsaturated fatty acids on infant cognitive function. Lipids 1998, 33: 973-980.

[10] Auestad N, Halter R, Hall RT, Blatter M, Bogle ML, Burks W, Erickson JR, Fitzgerald $\mathrm{KM}$, Dobson V, Innis SM, Singer LT, Montalto MB, Jacobs JR, Qiu WZ, Bornstein MH. Growth and development in term infants fed long-chain polyunsaturated fatty acids: A double-masked, randomized, parallel, pro- spective, multivariate study. Pediatrics 2001 , 108: 372-381.

[11] Auestad N, Scott DT, Janowsky JS, Jacobsen C, Carroll RE, Montalto MB, Halte R, Qiu W, Jacobs JR, Connor WE, Connor SL, Taylor JA, Neuringer M, Fitzgerald KM, Hall RT. Visual, cognitive, and language assessments at 39 months: A follow-up study of children fed formulas containing long-chain polyunsaturated fatty acids to 1 year of age. Pediatrics 2003, 112: E177-E183.

[12] Lucas A, Stafford M, Morley R, Abbott R, Stephenson T, MacFadyen U, Elias-Jones A, Clements H. Efficacy and safety of long-chain polyunsaturated fatty acid supplementation of infant-formula milk: a randomised trial. Lancet 1999, 354: 1948-1954.

[13] Makrides M, Neumann MA, Simmer K, Gibson RA. A critical appraisal of the role of dietary long-chain polyunsaturated fatty acids on neural indices of term infants: A randomized, controlled trial. Pediatrics 2000, 105: 32-38.

[14] Scott DT, Janowsky JS, Carroll RE, Taylor JA, Auestad N, Montalto MB. Formula supplementation with long-chain polyunsaturated fatty acids: Are there developmental benefits? Pediatrics 1998, 102: E591-E593.

[15] Jørgensen MH, Hernell O, Hughes E, Michaelsen KF. Is there a relation between docosahexaenoic acid concentration in mother's milk and visual development in term infants? J Pediatr Gastroenterol Nutr 2001, 32: $293-$ 296.

[16] Helland IB, Saarem K, Saugstad OD, Drevon CA. Fatty acid composition in maternal milk and plasma during supplementation with cod liver oil. Eur J Clin Nutr 1998, 52: 839-845.

[17] Henderson RA, Jensen RG, Lammi Keefe CJ, Ferris AM, Dardick KR. Effect of fish oil on the fatty acid composition of human milk and maternal and infant erythrocytes. Lipids 1992, 27: 863-869.

[18] Jensen CL, Maude M, Anderson RE, Heird WC. Effect of docosahexaenoic acid supplementation of lactating women on the fatty acid composition of breast milk lipids and maternal and infant plasma phospholipids. Am J Clin Nutr 2000, 71: 292S-299S.

[19] Makrides M, Neumann MA, Gibson RA. Effect of maternal docosahexaenoic acid (DHA) supplementation on breast-milk composition. Eur J Clin Nutr 1996, 50: 352-357.

[20] Cheruku SR, Montgomery-Downs HE, Farkas SL, Thoman EB, Lammi-Keefe CJ. Higher maternal plasma docosahexaenoic acid during pregnancy is associated with more mature neonatal sleep-state patterning. Am J Clin Nutr 2002, 76: 608-613; 2003, 78: 1227. 
[21] Colombo J, Kannass KN, Shaddy DJ, Kundurthi S, Maikranz JM, Anderson CJ, Blaga OM, Carlson SE. Maternal DHA and the development of attention in infancy and toddlerhood. Child Dev 2004, 75: 1254-1267.

[22] Innis SM, Gilley J, Werker J. Are human milk long-chain polyunsaturated fatty acids related to visual and neural development in breast-fed term infants? J Pediatr 2001, 139: 532-538.

[23] Innis SM, Gilley J, Werker J, Auestad N. Relation of essential n-6 and n-3 fatty acids to growth and neurodevelopment among breastfed infants to 1 year of age. Pediatr Res 2000, 47: 1705.

[24] Makrides M, Simmer K, Goggin M, Gibson RA. Erythrocyte docosahexaenoic acid correlates with the visual response of healthy, term infants. Pediatr Res 1993, 33: 425-427.

[25] Gibson RA, Neumann MA, Makrides M. Effect of increasing breast milk docosahexaenoic acid on plasma and erythrocyte phospholipid fatty acids and neural indices of exclusively breast fed infants. Eur J Clin Nutr 1997, 51: 578-584.

[26] Helland IB, Smith L, Saarem K, Saugstad OD, Drevon CA. Maternal Supplementation With Very-Long-Chain n-3 Fatty Acids During Pregnancy and Lactation Augments Children's IQ at 4 Years of Age. Pediatrics 2003, 111: e39-e44.

[27] Voigt RG, Jensen CL, Fraley JK, Rozelle J, Turcich M, Heird WC. Effects of maternal docosahexaenoic acid supplementation on neurodevelopmental function of breast-fed term infants at 12 and 30 months of age. J Dev Behav Pediatr 2000, 21: 384-385.

[28] Willatts P, Forsyth JS. The role of long-chain polyunsaturated fatty acids in infant cognitive development. Prostaglandins Leukot Essent Fatty Acids 2000, 63: 95-100.

[29] Lauritzen L, Jørgensen MH, Mikkelsen TB, Skovgaard IM, Straarup EM, Olsen SF, Høy CE, Michaelsen KF. Maternal fish oil supplementation in lactation: Effect on visual acuity and n-3 fatty acid content of infant erythrocytes. Lipids 2004, 39: 195-206.

[30] Lauritzen L, Hoppe C, Straarup EM, Michaelsen KF. Maternal fish oil supplemen- tation in lactation and growth during the first 2.5 years of life, Pediatr Res 2005, 58: 235242.

[31] Ulbak J, Lauritzen L, Hansen HS, Michaelsen KF. Diet and blood pressure in 2.5-y-old Danish children. Am J Clin Nutr 2004, 79: 10951102.

[32] Olsen J, Melby M, Olsen SF, Sørensen TIA, Aaby P, Andersen AMN, Taxbøl D, Hansen KD, Juhl M, Schow TB, Sørensen HT, Andresen J, Mortensen EL, Olsen AW, Søndergaard C. The Danish National Birth Cohort - its background, structure and aim. Scand J Public Health 2001, 29: 300-307.

[33] Greisen G, Michaelsen KF. Perinatal vækst. Ugeskr Læger 1989, 151: 1813-1816.

[34] Lyytinen P, Laakso ML, Poikkeus AM, Rita $\mathrm{N}$. The development and predictive relations of play and language across the second year. Scand J Psychol 1999, 40: 177-186.

[35] Welch AA, Lund E, Amiano P, Dorronsoro M, Brustad M, Kumle M, Rodriguez M, Lasheras C, Janzon L, Jansson J, Luben R, Spencer EA, Overvad K, Tjønneland A, Clavel-Chapelon F, Linseisen J, KlipsteinGrobusch K, Benetou V, Zavitsanos X, Tumino R, Galasso R, Bueno-de-Mesquita HB, Ocke MC, Charrondiere UR, Slimani N. Variability of fish consumption within the 10 European countries participating in the European Investigation into Cancer and Nutrition (EPIC) study. Public Health Nutr 2002, 5: 1273-1285.

[36] Jensen RG. Lipids in human milk. Lipids 1999, 34: 1243-1271.

[37] Slater A. Can measures of infant habituation predict later intellectual ability? Arch Dis Child 1997, 77: 474-476.

[38] Willatts P. Beyond the "couch potato" infant: how infants use their knowledge to regulate action, solve problems, and achieve goals. In: Bremner G, Slater A (Eds), Infant development: recent advances, Psychology Press, Hove, 1997, p 109-135.

[39] Fenson L, Bates E, Dale P, Goodman J, Reznick JS, Thal D. Measuring variability in early child language: Don't shoot the messenger. Child Dev 2000, 71: 323-328. 